\title{
Countereditorial
}

\section{A Common Sense Approach Resolves the Basement Membrane Controversy and the NIH Pima Indian Study}

\author{
J. R. Williamson and C. Kilo
}

The central issue of two recent editorials by Gunderson et al. [1] and by Siperstein et al. [2] concerns the interpretation of muscle capillary basement membrane (MCBM) measurements obtained from the NIH-sponsored Pima Indian study (a co-operative study involving our laboratory as well as that of Siperstein et al., co-ordinated by Dr. P. Bennett and associates). Siperstein, Feingold and Bennett [2] have interpreted the preliminary data as: 1) documenting the presence of MCBM thickening in approximately $50 \%$ of prediabetic Pima Indians, confirming Siperstein's earlier report of significant MCBM thickening in $50 \%$ of Caucasian prediabetics and supporting his previous observations and conclusions regarding MCBM thickening in diabetics, and 2) "demonstrating that differences in methodology, far from being minor, probably account for the failure of studies using glutaraldehyde-fixed tissue to observe quadriceps MCBM thickening in prediabetic subjects." Gunderson, Osterby and Lundbaek [1] question the validity of these interpretations and are concerned by apparent data discrepancies in this and in previous reports by Siperstein et al.

When the Pima data are examined critically in terms of their biological and statistical implications, and in the context of data previously published by Siperstein et al. [3], two points become clear: 1) the Pima data regarding fixative effects on the frequency of MCBM thickening in prediabetic and diabetic Pimas are inconclusive, and 2) data derived from osmium-fixed tissue in Siperstein's laboratory are not reproducible. In view of these findings, the interpretations of Pima data by Siperstein, Feingold and Bennett are untenable. It is ironical that the key to resolving the interpretation of the Pima Indian study lies in the data from normal Caucasians included in the study.
In several recent publications $[4,5,6]$, we have discussed in detail the issues involved in the basement membrane controversy, including the anomalous character of data (derived from osmium-fixed tissue) published by Siperstein relative to observations published by other investigators. The Pima study now provides data which, for the first time, unequivocally document that results obtained from osmium-fixed tissue are not reproducible in Siperstein's own laboratory. On the contrary, data generated in his laboratory from glutaraldehyde-fixed tissue are reproducible and are consonant with data published by other investigators (including our own) derived from osmium or from glutaraldehyde-fixed tissues [6].

Siperstein et al. alluded to only part of the problem when they stated that "for unknown technical reasons, all the values obtained with osmium fixation for normal, prediabetic and diabetic patients in the NIH (Pima) study were higher than those obtained earlier" [2]. They did not acknowledge that the very much higher MCBM width values obtained for osmium-fixed tissue from normal Caucasians in the Pima study are virtually identical to those from glutaraldehyde-fixed tissues. Thus, the very large fixative differences per se which they reported earlier in normal Caucasians are not substantiated in the Pima study. The implication of their final remark on this important issue, i.e., that data obtained with osmium-fixation are nevertheless reliable, provided that control determinations are carried out concomitantly, further misleads and falsely reassures the unsuspecting reader.

In order to fully understand the problem, we need only examine data shown in Table 1 which includes the Pima data shown in Table 1 of the editorial by Gunderson et al. [1] together with data from normal 
Table 1. Muscle capillary basement membrane width values published by Siperstein et al. in 1973 [3] together with values from the 1976 Preliminary Report on the Pima Indian Study [1]

\begin{tabular}{|c|c|c|c|c|}
\hline & & $\mathrm{n}$ & $\begin{array}{l}\text { Osmium } \\
\text { Mean } \pm \text { SD }(\AA)\end{array}$ & $\begin{array}{l}\text { Glutaraldehyde } \\
\text { Mean } \pm S D(\AA)\end{array}$ \\
\hline 1973 & $\begin{array}{l}\text { Normal } \\
\text { Caucasians }\end{array}$ & 20 & $1035 \pm 118$ & $1570 \pm 371$ \\
\hline \multirow[t]{4}{*}{$\begin{array}{l}\text { Pima } \\
(1976)\end{array}$} & $\begin{array}{l}\text { Normal } \\
\text { Caucasians }\end{array}$ & 20 & $1606 \pm 411$ & $1435 \pm 371$ \\
\hline & Normal Pimas & 18 & $1466 \pm 195$ & $1504 \pm 309$ \\
\hline & $\begin{array}{l}\text { Prediabetic } \\
\text { Pimas }\end{array}$ & 17 & $1646 \pm 432$ & $1548 \pm 470$ \\
\hline & $\begin{array}{l}\text { Diabetic } \\
\text { Pimas }\end{array}$ & 25 & $3069 \pm 951$ & $3040 \pm 1160$ \\
\hline
\end{tabular}

Caucasians previously published by Siperstein et al. [3], but not cited by them in their editorial [2]. The first point to note is that in the Pima data, means and standard deviations of MCBM width do not differ significantly for osmium versus glutaraldehyde-fixed tissues from normal Caucasians, prediabetic Pimas, or diabetic Pimas. Likewise, mean MCBM width of normal Pimas is the same for glutaraldehyde and for osmium-fixed tissues. The only significant fixativerelated data difference in the entire Pima study is that the standard deviation of mean MCBM width of normal Pimas, is approximately one-third smaller for osmium than for glutaraldehyde-fixed tissue (195 vs 309 , respectively, $\mathrm{P}<0.04$ that the variances are equal [7]). How then does one account for the higher frequency of MCBM thickening in osmium-fixed tissue from prediabetics and diabetics claimed by Siperstein et al.?

The increased frequency of MCBM thickening in osmium-fixed (compared to glutaraldehyde-fixed) tissue in these two groups is only evident in prevalence data obtained by determining how many prediabetics and diabetics have MCBM width values in excess of confidence limits derived from the mean and standard deviation of MCBM width of normal Pimas. Since the standard deviation of MCBM width values from osmium-fixed tissues was one third smaller than that of glutaraldehyde-fixed tissues, the upper confidence limit for osmium-fixed tissue will be correspondingly lower. Therefore, even though MCBM width values of prediabetics and diabetics are identical for the two fixatives, more of them will exceed upper limits of normal for osmium-fixed than for glutaraldehyde-fixed tissue from normal Pimas.

The likelihood that the small standard deviation of MCBM measurements in normal Pimas is a spurious, non-reproducible result is clearly seen when normal Caucasian data in the Pima study are viewed in the context of normal Caucasian data from Siperstein's 1973 study (Table 1). Note the very large differences both in mean MCBM width (1035 vs $1606, t$ $=5.972, \mathrm{P}<0.001)$ and in standard deviations $(188$ vs $411, \mathrm{P}<0.0005$ that variances are equal) of measurements obtained from osmium-fixed tissue in 1973 versus those in the Pima study. The magnitude of these differences is virtually identical to the differences between osmium and glutaraldehyde-fixed tissue in the 1973 study ( 1035 vs $1570, \mathrm{t}=6.146$, $\mathrm{P}<0.001$ and 118 vs $371, \mathrm{P}<0.0005$, respectively) which are not confirmed in Caucasians in the Pima study. The interpretations of the Pima data by Siperstein et al. hinge, therefore, on a single observation identical in nature to earlier observations on normal Caucasians which could not be reproduced in his own laboratory in the Pima study.

Although the failure in the Pima study to reproduce the fixative effect observed earlier in normal Caucasians might be attributed to different genetic backgrounds of the Caucasians sampled in the two studies, this would appear to be an unlikely explanation in view of the fact that we and others have not been able to demonstrate the fixative effect in several other samples of normal Caucasians from different geographic locations $[5,6]$.

These findings therefore raise serious questions regarding the reliability and credibility not only of the Pima data, but also for all of Siperstein's published data derived from osmium-fixed tissue.

On the contrary, data derived from glutaraldehyde-fixed tissue by Siperstein et al. are in close agreement in both studies (Table 1) and agree well with our own published data for glutaraldehyde-fixed tissue. We would also point out that in our comparative study of fixative effects, comparable results were obtained with osmium and with glutaraldehyde-fixed tissue [6]. Thus, primary glutaraldehyde fixation yields more consistent and reliable results even in Siperstein's laboratory than the osmium fixative they advocate!

One last important point deserves comment. Siperstein et al. consider that the higher frequency of MCBM thickening (in diabetics) they observed in osmium-fixed tissue than in glutaraldehyde-fixed tissue constitutes prima facie evidence that osmium is better (more sensitive) than glutaraldehyde for detection of MCBM thickening. This interpretation assumes that MCBM thickening is present in 100\% of diabetics. We have repeatedly pointed out that the demonstration of a high prevalence of MCBM thickening in newly diagnosed adult onset diabetics does not validate that assumption because of the well known fact that asymptomatic carbohydrate intolerance can be present for many years, even decades, in 
these subjects before they are diagnosed as diabetic. Thus, the high frequency of MCBM thickening in such subjects probably reflects duration, rather than presence or absence, of carbohydrate intolerance. Studies on juvenile onset diabetics (in whom the onset of carbohydrate intolerance can be dated much more reliably than for maturity onset diabetics) clearly indicate that MCBM thickening is uncommon (less than $10 \%$ ) in newly diagnosed diabetics but approaches $80 \%$ after a duration of 20 years or longer $[6,8]$.

The non-reproducible results in normal Caucasians and the spurious low standard deviation of MCBM width values of normal Pimas associated with osmium fixation in Siperstein's laboratory are indeed perplexing, but are best recognized as such. The rest of the Pima data then makes sense and is consistent with the majority of data published on MCBM thickening in kidney and in muscle in Caucasian diabetics $[6,9]$. Viewed in this way, the findings of the Pima Indian study are not inconclusive; the demonstration that results obtained with osmium fixation are not reproducible in Siperstein's laboratory provides a simple but logical explanation for the long standing, confusing controversy regarding the frequency of MCBM thickening in diabetics and the relationship of MCBM thickening to the insulin deficient state. In addition, the observations derived from glutaraldehyde-fixed tissue indicate that the prevalence of MCBM thickening and the relationship between MCBM thickening and duration of diabetes are similar in Pimas and in Caucasians.

\section{References}

1. Gundersen, H. J. G., Osterby, R., Lundbaek, K.: The basement membrane controversy. Diabetologia 15, 361-363 (1978)

2. Siperstein, M. D., Feingold, K. R., Bennett, P. H.: Hyperglycaemia and diabetic microangiopathy. Diabetologia 15, 365-367 (1978)

3. Siperstein, M. D., Raskin, P., Burns, H.: Electron microscopic quantification of diabetic microangiopathy. Diabetes 22, 514-524 (1973)

4. Kilo, C., Vogler, N., Williamson, J. R.: Muscle capillary basement membrane changes related to aging and to diabetes mellitus. Diabetes 21, 881-905 (1972)

5. Williamson, J. R., Rowold, E., Hoffmann, P., Kilo, C.: Influence of fixation and morphometric technics on capillary basement-membrane thickening prevalence data in diabetes. Diabetes 25, 604-613 (1976)

6. Williamson, J. R., Kilo, C.: Current status of capillary basement membrane disease in diabetes mellitus. Diabetes 26, 65-73 (1977)

7. Tests of hypotheses concerning the variances of two populations. In: Introduction to statistical analysis. Dixon, W. J., Massey, F. J., Jr. (Eds.), p. 106. New York: McGraw-Hill 1957

8. Williamson, J. R., Vogler, N., Kilo, C.: The natural history of basement membrane disease in diabetes mellitus. In: Proceedings of the Eighth Congress of the International Diabetes Federation, Brussels, July 1973. Malaisse, W. J., Pirart, J. (Eds.), pp. 424-428. Amsterdam: Excerpta Medica 1973

9. Osterby Hansen, R.: A quantitative estimate of the peripheral glomerular basement membrane in recent juvenile diabetes. Diabetologia 1, 97-100 (1965)

J. R. Williamson, M. D.

Department of Pathology

Washington University School of Medicine

660 South Euclid Avenue

St. Louis, MO 63110

USA 